\title{
Corticosterone induces growth hormone expression in pituitary somatotrophs during goose embryonic development
}

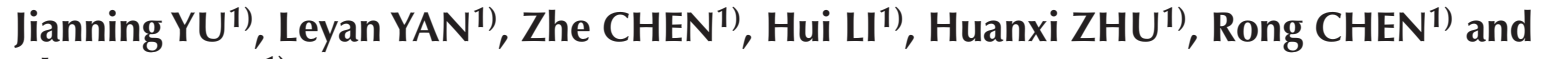 \\ ZhenDan SHI)

\begin{abstract}
${ }^{1)}$ Key Laboratory of Protected Agriculture Engineering in the Middle and Lower Reaches of Yangtze River, Ministry of Agriculture; Laboratory of Animal Breeding and Reproduction, Institute of Animal Science, Jiangsu Academy of Agricultural Sciences, Nanjing 210014, China
\end{abstract}

\begin{abstract}
Treatment of fetal rat and embryonic chicken with exogenous glucocorticoids induces premature differentiation of growth hormone $(\mathrm{GH})$ secreting cells. The effect of corticosterone (CORT) on somatotroph differentiation was mostly studied in pituitary cells in vitro. Currently, there is no evidence for glucocorticoid-mediated induction of somatotroph differentiation during pituitary development in bird species other than chicken. In this study, we sought to find out if in ovo injection of corticosterone into developing goose embryos could induce premature increase of GH in somatotrophs. On embryonic day (e) 15 , the albumen of fertile goose eggs was injected with $300 \mu \mathrm{l} \mathrm{of} 0.9 \%$ saline, $300 \mu \mathrm{l} 5 \times 10^{-8} \mathrm{M}$ CORT, or $300 \mu \mathrm{l} 5 \times 10^{-6} \mathrm{M}$ CORT. Embryos were allowed to develop until e20 and e 28 and isolated pituitaries were subjected to quantitative real-time PCR and immunocytochemistry to detect $G H$ mRNA and protein, respectively. At e20 and e28, blood from chorioallantoic vessels was subjected to radioimmunoassay for analysis of plasma GH protein. In ovo administration of exogenous corticosterone brought about a 2.5-fold increase in the expression of GH mRNA and increased the in situ expression of GH protein in goose pituitary cells, and enhanced plasma GH levels compared to that of the respective controls at e20. These findings prove that administration of glucocorticoid could stimulate the expression of GH in somatotrophs during goose embryonic development. Our results suggest the probable involvement of membrane glucocorticoid receptor in the corticosterone mediated expression of GH. Together with previously published data, our results suggest that corticosterone mediated induction of GH expression during embryonic development is relatively conserved among different vertebrates.
\end{abstract}

Key words: Corticosterone, Goose embryonic development, Growth hormone, Pituitary, Somatotroph

(J. Reprod. Dev. 64: 343-350, 2018)

$\mathbf{S}_{\mathrm{c}}^{\mathrm{o}}$ matotrophs, the most abundant of the five major types of endocrine cell of the anterior pituitary secretes growth hormone $(\mathrm{GH})$. Several studies have revealed the role of hormones of peripheral endocrine glands in regulating somatotroph differentiation during chick embryonic and rat fetal development [1].

Circulating corticosterone (CORT) concentrations increase more than fivefold between embryonic day 12 (e12) and e16 in the developing chick embryo [2], which is consistent with somatotroph differentiation. Interestingly, treatment of e12 pituitary cells with serum from e16 chick embryos increased the number of GH-secreting cells by 10 -fold [3]. This capacity of embryonic serum to induce pituitary somatotroph differentiation is suppressed by preabsorption of e16 serum with an antiserum against CORT [4]. These findings suggest the role of adrenal glucocorticoid CORT in inducing pituitary somatotroph differentiation during chicken embryonic development.

Substantial evidences indicate that CORT can both stimulate and modulate somatotroph differentiation during chicken and rat embryonic

Received: January 9, 2018

Accepted: May 14, 2018

Published online in J-STAGE: June 8, 2018

(C)2018 by the Society for Reproduction and Development

Correspondence: L Yan (e-mail: yanleyan198469@126.com)

This is an open-access article distributed under the terms of the Creative Commons Attribution Non-Commercial No Derivatives (by-nc-nd) License. (CC-BY-NC-ND 4.0: https://creativecommons.org/licenses/by-nc-nd/4.0/) development [4-8]. CORT stimulated GH cell differentiation in cells taken from fetal rat pituitary gland [6]. In vitro, CORT increased the number of cells containing or secreting GH protein in cultures of chick embryonic pituitary cells [9-12]. Administration of dexamethasone in drinking water of pregnant rats increased immunoreactive GH and GH mRNA in the pituitary gland of rat embryos at 17-18 days of gestation [7, 8]. In chicken embryos, administration of CORT markedly increased the abundance of GH cells at e14 [5].

So far, research has mostly evaluated the in vitro effects of CORT on somatotroph differentiation in chicken and rat embryos using pituitary cells. Few articles have focused on in vivo experiments to study pituitary cell differentiation. However, there has been no in vivo or in vitro investigations conducted to study goose embryonic somatotroph differentiation. We found that lower doses of CORT had a significant effect on goose somatotroph differentiation. This suggests that goose embryonic development is more sensitive than chicken to CORT. In the present study, we used goose embryos to evaluate the expression pattern of GH, growth hormone receptor (GHR) and CORT during the second half of goose embryogenesis. We further studied the effects of in ovo injection of different concentrations of exogenous CORT on the expression of $\mathrm{GH}$ in somatotrophs. 
Table 1. Primers used for the real-time quantitative PCR assay of genes

\begin{tabular}{lclcc}
\hline Gene name & Accession number & \multicolumn{1}{c}{ Primer sequences $\left(5^{\prime}-3^{\prime}\right)$} & $\begin{array}{c}\text { Annealing } \\
\text { temperature }\left({ }^{\circ} \mathrm{C}\right)\end{array}$ & $\begin{array}{c}\text { PCR product } \\
(\mathrm{bp})\end{array}$ \\
\hline$\beta$-actin & L08165.1 & $\begin{array}{l}\text { upstream: TGACGCAGATCATGTTTGAGA } \\
\text { downstream: GCAGAGCGTAGCCCTCATAG }\end{array}$ & 60 & 159 \\
GH & NM_001310345.1 & $\begin{array}{l}\text { upstream: CACTGTGATCACCCTGGGAT } \\
\text { downstream: TTGGTGTGCTCTGGTCCTC } \\
\text { upstream: AGCCAGCCATGACAACTACAAGAC }\end{array}$ & 60 & 97 \\
KC242242.1 & DQwnstream: TCGTCACTCAGGAGCCTGTCAG & 59 & 129 \\
upstream: AGCAGCAGGTCAGAAACC & 60 & 269 \\
\hline
\end{tabular}

\section{Materials and Methods}

\section{Animals and injections}

Fertilized goose eggs were purchased from Sunlake Swan Farm, Henglin Township, Changzhou, Jiangsu Province, China. Fertile goose eggs were placed in a humidified incubator (Humidity: $55 \%$ to $60 \%$; Hengxin Incubator Equipment Corporation, Nanjing, Jiangsu) at 36.7 to $38.2^{\circ} \mathrm{C}$. The normal incubation period for a goose egg is $31 \mathrm{~d}$. Eggs were examined by candling at $15 \mathrm{~d}$ of development to detect the presence of live embryos. Fertile goose eggs were placed with their smaller apical ends directed upward and the ends were swabbed with $70 \%$ ethanol. A small hole was made using an 18 -gauge needle and the treatment solutions were injected into the albumen at a depth of approximately $10 \mathrm{~mm}$ using a 25 -gauge needle attached to a tuberculin syringe on e15. The hole at the site of injection was sealed with melted paraffin and the eggs were returned to the incubator until the appropriate developmental stage.

Fertile eggs were divided into 3 groups $(n=90,30$ eggs in each group) and treated (injected with the respective treatment solutions) as follows: control group, $300 \mu 1$ of $0.9 \%$ saline/egg; low-concentration CORT (CS-L) group, $300 \mu \mathrm{l}$ of $5 \times 10^{-8} \mathrm{M}$ CORT/egg; and highconcentration CORT (CS-H) group, $300 \mu 1$ of $5 \times 10^{-6} \mathrm{M} \mathrm{CORT/egg.}$ CORT used for the injection was first dissolved in $100 \%$ ethanol to a concentration of $1 \times 10^{-3} \mathrm{M}$ and then diluted in saline to obtain final concentrations of $5 \times 10^{-8}$ and $5 \times 10^{-6} \mathrm{M}$ treatment solutions.

\section{RNA extraction and quantitative real-time polymerase chain reaction ( $q P C R$ )}

qPCR was used for quantification of mRNA expression levels of $\beta$-actin (housekeeping gene), GH, GHR and glucocorticoid receptor (GR) derived from pituitary gland of goose embryos at e15, e20, e25, e28, and e30. Total RNA was extracted from pituitary glands using TRIzol reagent (Invitrogen, Carlsbad, CA, USA) and the complementary DNA (cDNA) was synthesized by reverse transcription using a Rever Tra Ace qPCR RT Kit (Toyobo, Osaka, Japan) following the manufacturer's instructions. PCR was carried out in a final reaction volume of 50- $\mu 1$ containing SYBR Green I master mix (Toyobo). Details of primer sequences and annealing temperatures used in the present study are shown in Table 1. ABI PRISM-7500 real-time PCR system (Applied Biosystems; Foster City, CA, USA) was used to detect amplification products. On completion of qPCR, threshold cycle $(\mathrm{Ct}$, defined as the cycle at which a statistically significant increase in the magnitude of the signal generated by PCR was first detected) values were calculated using sequence detection software (SDS) version 1.2.2 (Applied Biosystems). Gene expression levels were analyzed using the $2^{-\Delta \Delta \mathrm{CT}}$ method and normalized to $\beta$-actin (internal housekeeping gene).

\section{Measurement of CORT concentrations}

Blood was collected from the chorioallantoic vessel of goose embryos at e15, e20, e25, and e30, respectively, into tubes containing $10 \mu 1$ EDTA [0.5 M (pH 8)] (prevent clotting) and centrifuged at $14,000 \times g$ for $10 \mathrm{~min}$ to isolate plasma. All plasma samples were stored at $-20^{\circ} \mathrm{C}$ until further use. Plasma CORT concentrations were measured quantitatively using an ELISA Kit (North Institute of Biological Technology, Beijing, China) according to the manufacturer's instructions. The assay sensitivity was less than $0.2 \mathrm{ng} / \mathrm{ml}$. The intra- and inter-assay coefficients of variation were lower than $10 \%$. The r-value of standard curves of all assays was greater than 0.99. CORT concentrations were normalized to the level of CORT detected in embryonic goose blood at e15.

\section{Immunohistochemistry (IHC) for localizing GH protein in pituitary cells}

Pituitary glands were isolated from goose embryos ( $\mathrm{n}=10$ each) belonging to three experimental groups: control, CS-L, and CS-H, at e20 and e28. Dissected pituitary glands were fixed with 3.7\% formaldehyde in phosphate-buffered saline (PBS) for $20 \mathrm{~min}$. Serial sections measuring 4-mm each were cut from paraffin-embedded blocks and mounted on poly-L-lysine-coated glass slides. For antigen retrieval, slides were immersed in EDTA buffer $(\mathrm{pH} 9)$ and heated in a microwave oven (Moderate fire for $8 \mathrm{~min}$, stopping for $8 \mathrm{~min}$ and low fire for $7 \mathrm{~min}$ ). After sequential deparaffinization and rehydration, sections were treated with $0.3 \% \mathrm{H}_{2} \mathrm{O}_{2}$ for $15 \mathrm{~min}$ to quench endogenous peroxidase and blocked with $1.5 \%$ normal horse serum (Santa Cruz Biotechnology, Santa Cruz, CA) (diluted in PBS buffer) for $60 \mathrm{~min}$. Sections were then incubated overnight with primary rabbit polyclonal anti-goose $\mathrm{GH}$ (prepared in our own laboratory, GenBank: AAN37412.1) diluted 1:100 with 0.05 $\mathrm{M}$ Tris- $\mathrm{HCl}$ buffer ( $\mathrm{pH}$ 7.4) containing $1 \%$ bovine serum albumin. Sections were washed twice with PBS and incubated with horseradish peroxidase-conjugated mouse anti-rabbit IgG secondary antibody 
(1:2000) (Invitrogen, USA) for $60 \mathrm{~min}$. Sections were then treated with 3,3-diaminobenzidinetetrahydrochloride (DAB) substrate, stained with hematoxylin and viewed under a Nikon Eclipse Ci microscope (Nikon, Tokyo, Japan). Negative control slides prepared by omitting the primary antibody incubation step were included for each staining experiment. GH-containing cells were visualized under the Nikon Eclipse $\mathrm{Ci}$ microscope and the results were expressed as mean gray value per unit area as analyzed by ImageJ software(https://imagej. nih.gov/ij/download.html).

Radioimmunoassay (RIA) for detecting GH protein in plasma

Blood was collected from the chorioallantoic vessel of goose embryos on e 20 and e 28 into tubes containing $10 \mu$ LDTA $[0.5 \mathrm{M}(\mathrm{pH}$ 8)] and centrifuged at $14,000 \times g$ for $10 \mathrm{~min}$ to isolate plasma. Plasma samples were stored at $-20^{\circ} \mathrm{C}$ until further use. Concentration of $\mathrm{GH}$ in the plasma was measured using 125I RIA kit (North Institute of Biological Technology, Beijing, China) with an inter-assay coefficient of variation of $5.6 \%$ and a sensitivity of $2.5 \mathrm{ng} / \mathrm{ml}$. All protocols were performed as per the manufacturer's instructions. All test samples were assayed in duplicate. Concentration of GH in the plasma was normalized to the level of GH detected in the control group (without CORT injection).

\section{Statistical analysis}

Data are expressed as the mean \pm SEM. Differences in gene and protein expression in pituitary cells were analyzed using analysis of variance (ANOVA). Statistical analyses were performed using Statistical Package for Social Sciences software (SPSS version 17.0, IBM, Armonk, New York). P value $<0.05$ was considered statistically significant. Statistical graphs were plotted using Sigma Plot software (version 11.0, Systat Software International, San Jose, California).

\section{Results}

Concomitant increase of pituitary GH and plasma CORT during goose embryonic development

Results depicting plasma levels of CORT and increased expression of GH and GHR mRNA in the pituitary gland are shown in Fig. 1. Expression of GH and its receptor transcript gradually increased in the pituitary glands from e 15 to e 30 before gosling hatching. The relative amount of GH mRNA at e20, e25, and e30 development was approximately 50, 80, and 120 times higher than that at e15, respectively. Although the fold change of GHR mRNA expression was not as high as GH mRNA, it was consistent with GH mRNA expression during development. The expression pattern of CORT in the plasma was similar to that of the expression of GH in the pituitary gland during goose embryonic development, with relative levels of CORT at e20, e25, and e30 development being approximately 1.6, 1.9, and 2.7 times higher than that at $15 \mathrm{~d}$, respectively. Thus, increase in the pituitary expression of GH corresponded with increased plasma CORT levels during the second half of goose embryogenesis.

\section{In vivo, CORT modulates somatotrophs expressing GH}

Change in plasma GH protein levels after in ovo injection of exogenous CORT: Blood was collected from the chorioallantoic vessel of goose embryos on e20 and e28. Plasma GH protein levels

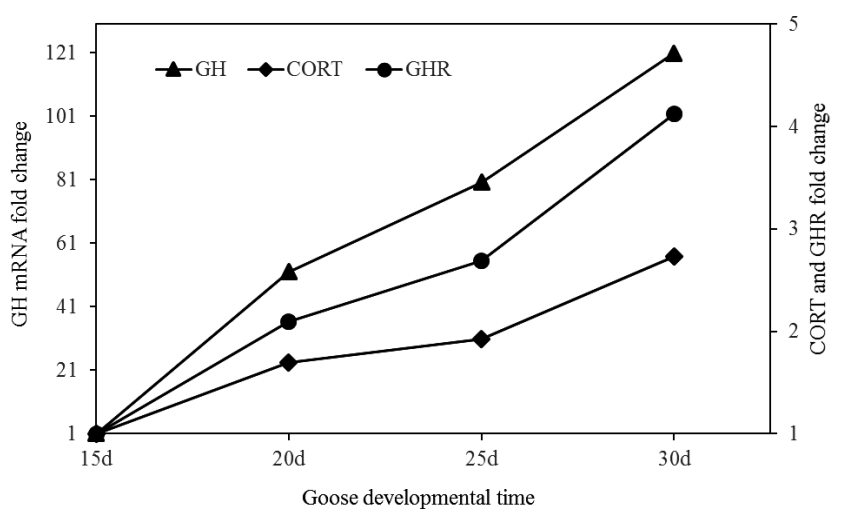

Fig. 1. Expression pattern of growth hormone $(\mathrm{GH})$, growth hormone receptor (GHR) and corticosterone (CORT) during goose embryonic development. Pituitary glands were obtained from goose embryos at e15, e20, e25, and e30. Total RNA was extracted for qPCR analysis. The level of GH (left axis) and expression of GHR (right axis) mRNA were expressed using the $2^{-\Delta \Delta C T}$ method and normalized to that of the internal housekeeping gene, $\beta$-actin (left axis). Blood was collected from goose embryos at e15, e20, e25, and e30. Serum was subjected to enzyme linked immunosorbant assay (ELISA) to detect plasma corticosterone (CORT) concentration using an ELISA quantitative diagnostic kit. The concentration of CORT is represented relative to its level in e15 embryonic goose blood (right axis).

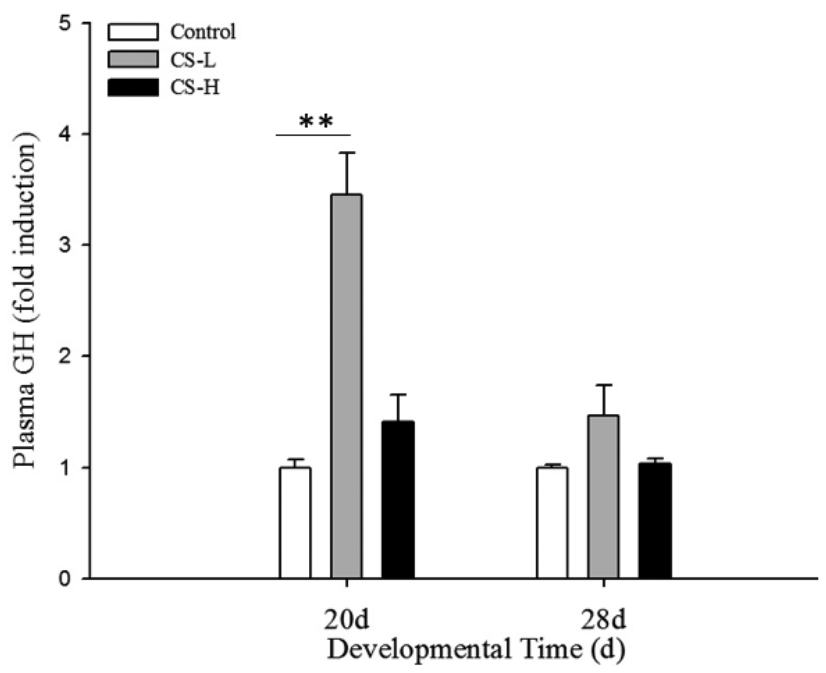

Fig. 2. Effect of in ovo injection of corticosterone (CORT) on plasma levels of growth hormone (GH). The albumen of fertile goose eggs was injected at e15 with $300 \mu \mathrm{l}$ of $0.9 \%$ saline (control), $300 \mu \mathrm{l}$ of low-concentration corticosterone (CORT) diluted with saline (CS-L, $5 \times 10^{-8} \mathrm{M}$ ), or $300 \mu \mathrm{l}$ of high-concentration CORT diluted with saline (CS-H, $\left.5 \times 10^{-6} \mathrm{M}\right)$. Serum from the chorioallantoic vessels was subjected to GH radioimmunoassay at e20 and e28. Results are represented as fold changes in the level of GH compared to that of the respective control groups from three independent trials. ${ }^{* *}$ indicates statistical significance at $\mathrm{P}<0.01$. 


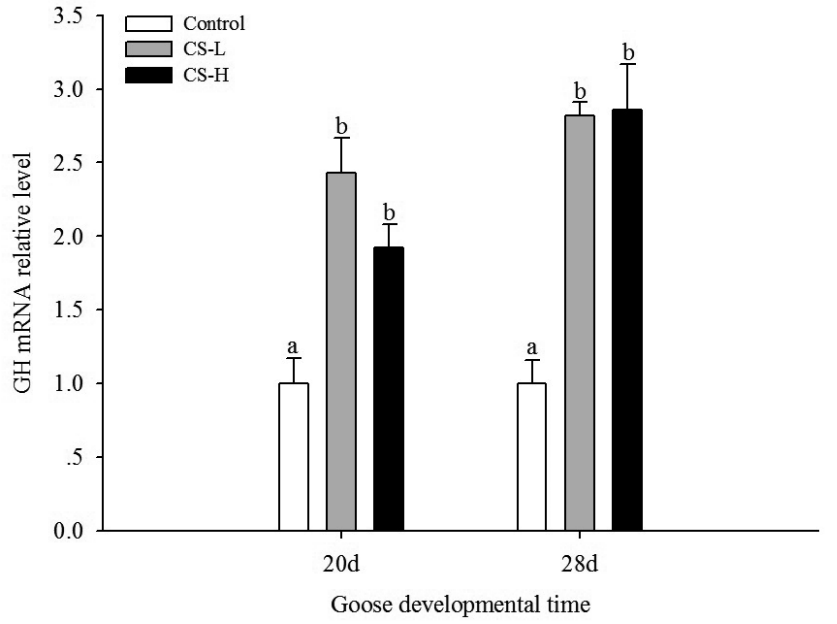

Fig. 3. Expression of growth hormone (GH) mRNA in pituitary cells after administration of corticosterone (CORT). The albumen of fertile goose eggs was injected at e15 with $300 \mu \mathrm{l}$ of $0.9 \%$ saline (control), $300 \mu \mathrm{l}$ of low-concentration corticosterone (CORT) diluted with saline (CS-L, $\left.5 \times 10^{-8} \mathrm{M}\right)$, or $300 \mu \mathrm{l}$ of high concentration of CORT diluted with saline (CS-H, $\left.5 \times 10^{-6} \mathrm{M}\right)$. Pituitary glands were collected at e20 and e28 and total RNA was extracted for qPCR analysis. The level of GH mRNA is expressed using the $2^{-\triangle \Delta C T}$ method and normalized to that of the internal housekeeping gene, $\beta$-actin. The results are representative of three independent experiments. a, b: Different lowercase letters indicate a significant difference in the same group $(\mathrm{P}<0.05)$.

detected by RIA are shown in Fig. 2. At e20, significantly elevated serum GH level was detected in the CS-L (low-concentration CORT treatment) group compared to that of the control $(\mathrm{P}<0.01)$. No significant increase was seen in the serum GH level in the CS-H (high-concentration CORT treatment) group compared to that of the control group. At e28, neither low- nor high-concentration CORT treatment could induce a significant increase in plasma GH level.

Change in the expression of GH mRNA in pituitary cells before and after administration of exogenous CORT: At e20 and e28, the expression of GH mRNA was detected in the pituitary gland of goose embryos by qPCR. Relative levels of GH mRNA are shown in Fig. 3. At e20 and e28, significantly increased expression of GH mRNA was seen in both CS-L and CS-H (low-and-high-concentration CORT treatment) groups compared to that of the control group $(\mathrm{P}<0.05)$.

Effect of CORT on the expression of GH protein in pituitary cells: Pituitary gland from goose embryos were fixed, cut into serial sections and stained with primary anti-GH antibodies and a secondary antibody. The expression of GH protein in pituitary sections from e 20 and e 28 goose embryos is shown in Figs. 4 and 5, respectively. A, C, and E in Figs. 4 and 5 represent IHC results of pituitary glands, while $\mathrm{B}, \mathrm{D}$, and $\mathrm{F}$ indicate surface plot images of $\mathrm{A}, \mathrm{C}$, and $\mathrm{E}$, respectively. A and B represent the control group without CORT; $\mathrm{C}$ and D represents the low-concentration CORT (CS-L) treatment group; E and F represents the high-concentration CORT (CS-H) treatment group. The brown area seen in Fig. 4-C is significantly larger than that in Fig. 4-A and -E. Surface plots indicate presence of deeper gray in Fig. 4-D (CS-L group) than that in the control and CS-H groups (Fig. 4-B and -F). The mean gray value of IHC results for the above three groups are shown in Fig. 4-G, indicating the relative level of $\mathrm{GH}$ protein expression in pituitary cells. The expression of GH protein increased to a maximum and was significantly higher in the CS-L group compared to that of the control and CS-H groups $(\mathrm{P}<0.05)$ (Fig. 4-G). Although the bar chart indicated higher levels of GH protein in the CS-H group than in the control, statistically, no significant difference was detected in the expression of $\mathrm{GH}$ protein between these groups $(\mathrm{P}>0.05)$ (Fig. 4-G). However, results represented in Fig. 5 suggested no significant difference between the three groups $(\mathrm{P}>0.05)$ neither from IHC image results (Fig. 5-A-F) nor from the mean gray values (Fig. 5-G).

\section{Change in the expression of GR mRNA in pituitary cells after in ovo injection of exogenous CORT}

GR mRNA was detected by qPCR from e20 and e2 8 goose embryos. Relative levels of GR mRNA are shown in Fig. 6. At e20, significantly enhanced expression of GR mRNA was detected in the CS-L (low-concentration CORT treatment) group compared to that of the control $(\mathrm{P}<0.05)$. No significant increase was seen in the expression of GR mRNA in the CS-H (high-concentration CORT treatment) group compared to that of the control group. However, at e28, neither low- nor high-concentration CORT treatment could induce a significant increase in the expression of GR mRNA compared to that of the control group $(\mathrm{P}>0.05)$.

\section{Discussion}

Glucocorticoid is a metabolic regulatory hormone secreted by the adrenal cortex. Secretion of animal glucocorticoid is regulated mainly by the hypothalamus-anterior pituitary-adrenal cortex axis. Primary physiological functions of glucocorticoid include promotion of gluconeogenesis, protein metabolism of extrahepatic tissue, and catabolism of fat. The above-mentioned functions of glucocorticoid relate to animals after their birth. So far, the role of glucocorticoid during embryonic development has not yet been elucidated.

In the present study, we examined the role of glucocorticoid in goose embryonic development. We found that the expression of GH mRNA in the pituitary gland was synchronized with that of plasma CORT levels during the second half of goose embryogenesis. During chicken embryogenesis, GH-producing cells functionally differentiate by e12 and coincide with an increase in circulating CORT $[13,14]$. Similarly, somatotroph differentiation in fetal rat and mice around e16 was found to be consistent with an increase in peripheral CORT [15].

In the present study, in ovo administration of exogenous CORT into goose eggs brought about a 2.5 -fold increase in the expression of GH mRNA and increased the in situ expression of GH protein in pituitary cells along with elevated levels of plasma GH protein compared to that of the respective controls at e20. In previous studies, when CORT was injected into developing chick embryos on e11 and pituitary cells were subjected to GH reverse hemolytic plaque assays (RHPA), it was found that CORT significantly increased GH secretors by e14 $[5,16]$. In rat embryos, dexamethasone treatment induced $\mathrm{GH}$ and GH mRNA accumulation in the fetal pituitary gland on e17-18 compared to that of the control fetus wherein substantial expression 

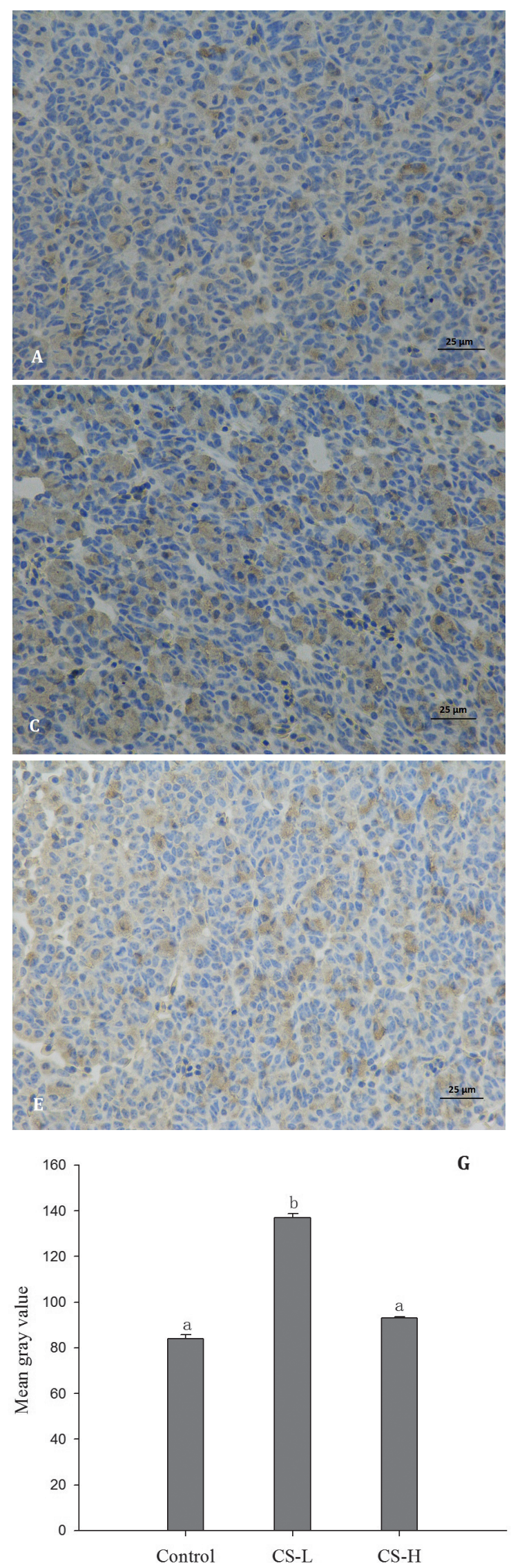
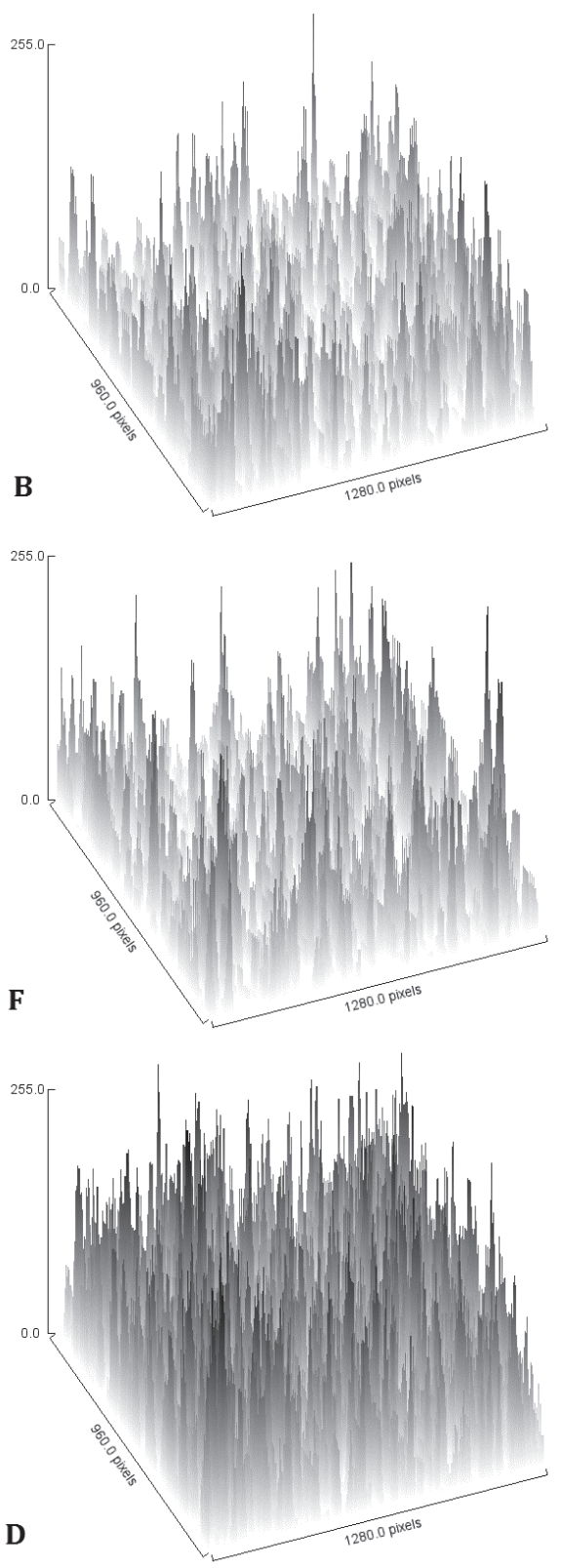

Fig. 4. Effect of corticosterone (CORT) administration on the level of growth hormone $(\mathrm{GH})$ protein in pituitary glands at e20 goose embryos. Pituitary glands were obtained from e20 goose embryos and subjected to GH immunohistochemistry (IHC). Representative images are shown in A, C, and E. (A) IHC results for GH expression in sliced pituitary gland without CORT injection (control). (B) Surface plot of (A) created using Image J $1.50 \mathrm{i}$ software. (C) IHC results of $\mathrm{GH}$ expression in sliced pituitary gland treated with low-concentration CORT (5 $\left.\times 10^{-8} \mathrm{M}\right)(\mathrm{CS}-\mathrm{L})$. (D) The surface plot of $(\mathrm{C})$ created using Image $1.50 \mathrm{i}$ software. (E) $\mathrm{IHC}$ results of $\mathrm{GH}$ expression in sliced pituitary gland treated with high-concentration CORT $\left(5 \times 10^{-6} \mathrm{M}\right)(\mathrm{CS}-\mathrm{H})$. (F) The surface plot of $(\mathrm{E})$ created using ImageJ $1.50 \mathrm{i}$ software. $(\mathrm{G})$ The mean gray value determined using ImageJ 1.50i software indicates the relative level of GH protein in the three groups: control, CS-L, and CS-H. The values are the mean \pm SEM. a, b: Different lowercase letters indicate a significant difference in the same group $(\mathrm{P}<0.05)$. 

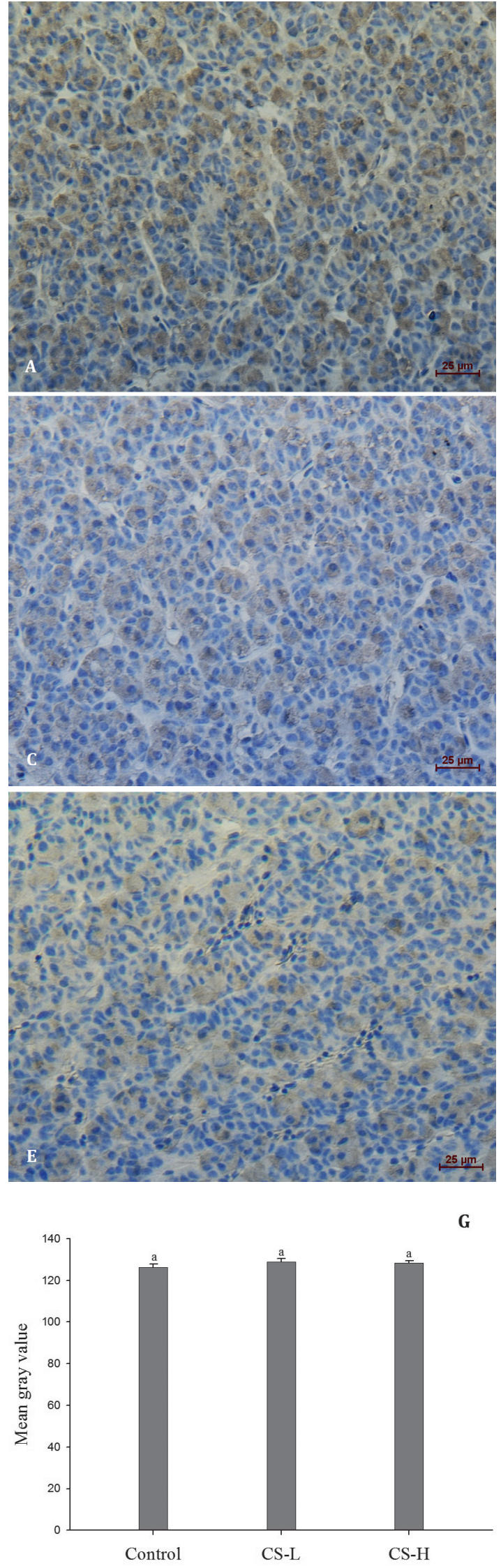
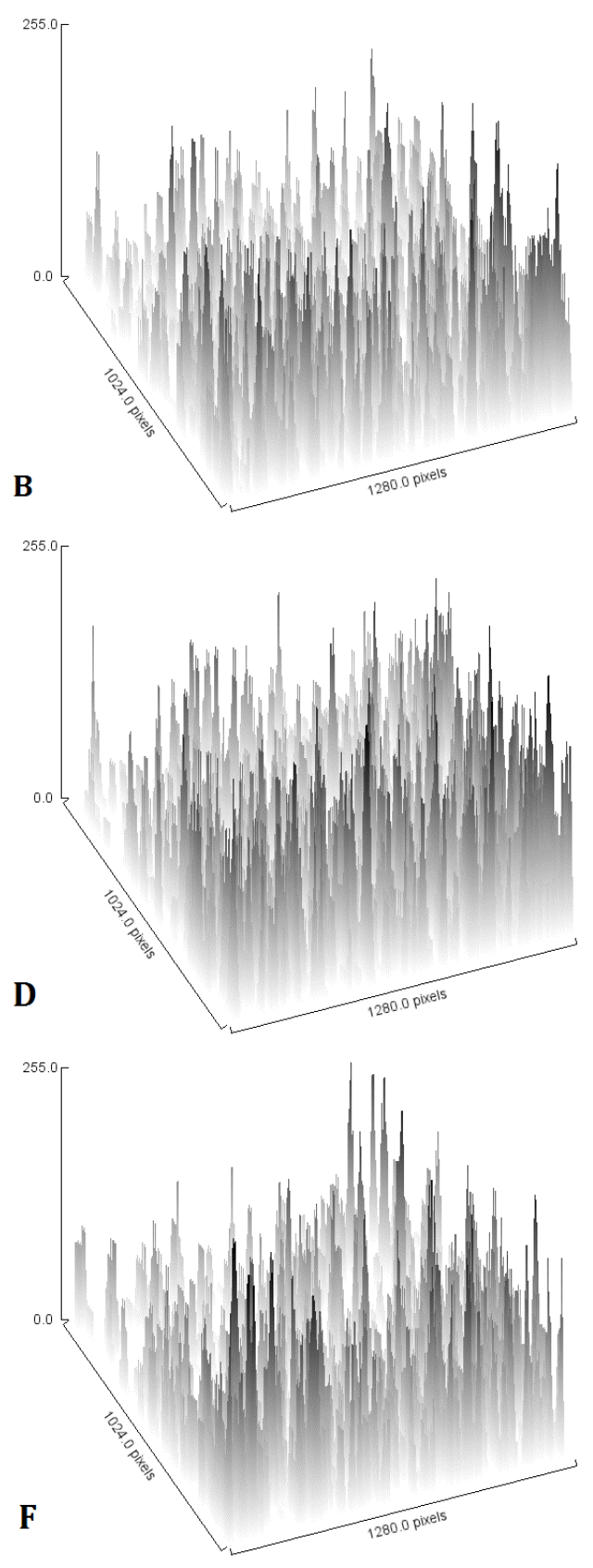

Fig. 5. Effect of exogenous corticosterone (CORT) administration on the level of growth hormone $(\mathrm{GH})$ protein in pituitary glands at e 28 goose embryos. Pituitary glands were obtained from e28 goose embryos and subjected to $\mathrm{GH}$ immunohistochemistry (IHC). Representative images are shown in $\mathrm{A}, \mathrm{C}$, and $\mathrm{E}$. (A) IHC results for $\mathrm{GH}$ expression in sliced pituitary gland without CORT injection (control). (B) Surface plot of (A) created using Image J 1.50i software. (C) IHC results for GH expression in sliced pituitary gland treated with low-concentration CORT $\left(5 \times 10^{-8} \mathrm{M}\right)(\mathrm{CS}-$ L). (D) Surface plot of (C) created using ImageJ 1.50i software. (E) IHC results for GH expression in sliced pituitary gland treated with highconcentration CORT $\left(5 \times 10^{-6} \mathrm{M}\right)(\mathrm{CS}-\mathrm{H})$. (F) Surface plot of $(\mathrm{E})$ created using ImageJ 1.50i software. $(\mathrm{G})$ The mean gray value determined using ImageJ $1.50 \mathrm{i}$ software indicates the relative level of $\mathrm{GH}$ protein in the three groups: control, CS-L, and CS-H. The values are the mean \pm SEM. $\mathrm{a}, \mathrm{b}$ : Different lowercase letters indicate a significant difference in the same group $(\mathrm{P}<0.05)$. 


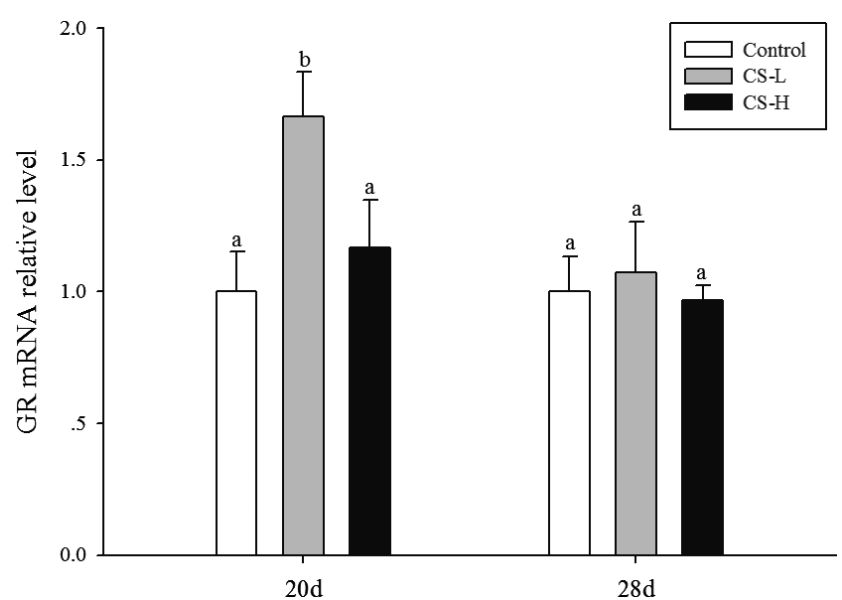

Fig. 6. Expression of glucocorticoid receptor (GR) mRNA in pituitary cells after corticosterone (CORT) administration. The albumen of fertile goose eggs was injected at e 15 with $300 \mu$ of $0.9 \%$ saline (control), $300 \mu \mathrm{l}$ of low-concentration corticosterone diluted with saline (CS-L, $\left.5 \times 10^{-8} \mathrm{M}\right)$, or $300 \mu \mathrm{l}$ of high concentration of corticosterone diluted with saline $\left(\mathrm{CS}-\mathrm{H}, 5 \times 10^{-6} \mathrm{M}\right)$. Pituitary glands were isolated at e20 and e 28 and total RNA was extracted for $\mathrm{qPCR}$ analysis. The level of GR mRNA are expressed using the $2^{-\Delta \Delta C T}$ method and normalized to that of the internal housekeeping gene, $\beta$-actin. The results are representative of three independent experiments. a, b: Different lowercase letters indicate a significant difference in the same group $(\mathrm{P}<0.05)$.

of GH was not yet initiated [8]. These results confirm the fact that glucocorticoid treatment could induce premature differentiation of GH cells and promote secretion of GH by pituitary cells in goose, chicken, and rat. Thus far, the available date suggests the effects of glucocorticoid on somatotrophs expressing GH to be possibly conserved among different species.

In this work, we showed that a single dose of exogenous CORT could induce in vivo expression of GH in somatotrophs in goose. This significant ability of CORT to enhance the level of GH protein was seen only at e20, but not at e28, although CORT could enhance the expression of GH mRNA at both e20 and e28. This could be because of the already elevated levels of CORT at e28 (as shown in Fig. 1), which renders the cell insensitive to the presence of externally administered CORT and hence, shows no additional effect on the expression of GH protein. On the other hand, no significant effect was seen in the expression of GH protein by administering high concentrations of CORT, indicating the sensitivity of goose embryonic somatotrophs to CORT concentration. GR acts as a transcription factor in mediating the biological effects of glucocorticoids [17]. The activated GR translocate into the nucleus, binds glucocorticoid, and controls specific gene transcription [18]. In somatotrophs of a normal pituitary gland, GR is possibly involved in the rapid induction of the GH gene transcription by CORT [19]. Our results show that in ovo administration of exogenous CORT brought about correspondingly identical changes in the expression of membrane GR and GH. Higher concentration of CORT had no effect on the expression of GH probably because of the absence of higher levels of GR (Fig. 6), limiting the formation of CORT-receptor complex that could translocate to the nucleus to initiate gene transcription. In the present study, results related to GR provide additional proof for the involvement of GR in CORT induced GH expression by somatotrophs. Taken together, our results suggest that the effect of CORT on the expression of GH in somatotrophs of goose embryonic pituitary cells might be mediated by the membrane GR.

Several in vitro experiments on cultured pituitary cells have provided further evidence related to the involvement of glucocorticoid in the functional differentiation of somatotrophs during embryonic development. Few studies have examined the mechanism of action underlying CORT induced expression of GH gene $[4,6,9,11$, 20]. In vitro, protein synthesis inhibitors completely inhibited the glucocorticoid-induced GH mRNA expression in both, mice and chick embryonic pituitary cells, suggesting the absence of a direct involvement of glucocorticoid in this process [20,21]. Studies have proved that in vitro, phosphatidylinositol 3-kinase might possibly be involved in the rapid induction of gene transcription of GH by glucocorticoids [19]. A recent study has demonstrated the involvement of Ras- and ERK 1/2-mediated transcriptional events requiring histone deacetylase activity in the glucocorticoid mediated induction of pituitary GH during chicken embryonic development [22]. Additional research on the molecular mechanism involved in the glucocorticoid-mediated induction of pituitary GH is therefore required for better understanding of the process.

In conclusion, a single in ovo injection of exogenous CORT significantly elevated the levels of GH mRNA, immunoreactive GH and plasma GH in both pituitary somatotrophs and blood. These results, for the first time, provide strong evidence that glucocorticoid could induce $\mathrm{GH}$ expression in somatotrophs during the development of pituitary gland in a bird species other than chicken. Together with previously published data, results from the present study provide comprehensive evidence of the direct involvement of glucocorticoids in the expression of $\mathrm{GH}$ by pituitary cells during vertebrate embryonic development. Although further studies are required for elucidating the molecular mechanisms underlying glucocorticoid-induced expression of $\mathrm{GH}$, the findings of the present study might provide important insights into glucocorticoid-induced changes in other tissues during embryonic development.

\section{Acknowledgments}

The authors thank Prof Tom E Porter (Department of Animal and Avian Sciences, University of Maryland, College Park, MD) for generously providing chicken GH primary antibody and his suggestions for this study. This work was supported by the Natural Science Foundation of Jiangsu Province (BK20150546) and the Fund for Independent Innovation of Agricultural Sciences in Jiangsu Province [CX(14)2068].

\section{References}

1. Porter TE. Regulation of pituitary somatotroph differentiation by hormones of peripheral endocrine glands. Domest Anim Endocrinol 2005; 29: 52-62. [Medline] [CrossRef]

2. Jenkins SA, Porter TE. Ontogeny of the hypothalamo-pituitary-adrenocortical axis in the chicken embryo: a review. Domest Anim Endocrinol 2004; 26: 267-275. [Medline] [CrossRef]

3. Porter TE, Couger GS, Morpurgo B. Evidence that somatotroph differentiation during 
chicken embryonic development is stimulated by a blood-borne signal. Endocrinology 1995; 136: 3721-3728. [Medline] [CrossRef]

4. Morpurgo B, Dean CE, Porter TE. Identification of the blood-borne somatotrophdifferentiating factor during chicken embryonic development. Endocrinology 1997; 138: 4530-4535. [Medline] [CrossRef]

5. Dean CE, Morpurgo B, Porter TE. Induction of somatotroph differentiation in vivo by corticosterone administration during chicken embryonic development. Endocrine 1999; 11: 151-156. [Medline] [CrossRef]

6. Sato K, Watanabe YG. Corticosteroids stimulate the differentiation of growth hormone cells but suppress that of prolactin cells in the fetal rat pituitary. Arch Histol Cytol 1998; 61: 75-81. [Medline] [CrossRef]

7. Nogami H, Tachibana T. Dexamethasone induces advanced growth hormone expression in the fetal rat pituitary gland in vivo. Endocrinology 1993; 132: 517-523. [Medline] [CrossRef]

8. Nogami H, Yokose T, Tachibana T. Regulation of growth hormone expression in fetal rat pituitary gland by thyroid or glucocorticoid hormone. Am J Physiol 1995; 268: E262E267. [Medline]

9. Bossis I, Nishimura S, Muchow M, Porter TE. Pituitary expression of type I and type II glucocorticoid receptors during chicken embryonic development and their involvement in growth hormone cell differentiation. Endocrinology 2004; 145: 3523-3531. [Medline] [CrossRef]

10. Dean CE, Porter TE. Regulation of somatotroph differentiation and growth hormone (GH) secretion by corticosterone and GH-releasing hormone during embryonic development. Endocrinology 1999; 140: 1104-1110. [Medline] [CrossRef]

11. Fu X, Porter TE. Glucocorticoid induction of lactotrophs and prolactin gene expression in chicken embryonic pituitary cells: a delayed response relative to stimulated growth hormone production. Endocrinology 2004; 145: 1322-1330. [Medline] [CrossRef]

12. Porter TE, Dean CE, Piper MM, Medvedev KL, Ghavam S, Sandor J. Somatotroph recruitment by glucocorticoids involves induction of growth hormone gene expression and secretagogue responsiveness. J Endocrinol 2001; 169: 499-509. [Medline] [CrossRef]
13. Jenkins SA, Muchow M, Richards MP, McMurtry JP, Porter TE. Administration of adrenocorticotropic hormone during chicken embryonic development prematurely induces pituitary growth hormone cells. Endocrinology 2007; 148: 3914-3921. [Medline] [CrossRef]

14. Porter TE, Ghavam S, Muchow M, Bossis I, Ellestad L. Cloning of partial cDNAs for the chicken glucocorticoid and mineralocorticoid receptors and characterization of mRNA levels in the anterior pituitary gland during chick embryonic development. Domest Anim Endocrinol 2007; 33: 226-239. [Medline] [CrossRef]

15. Mastorakos G, Ilias I. Maternal and fetal hypothalamic-pituitary-adrenal axes during pregnancy and postpartum. Ann N Y Acad Sci 2003; 997: 136-149. [Medline] [CrossRef]

16. Bossis I, Porter TE. Ontogeny of corticosterone-inducible growth hormone-secreting cells during chick embryonic development. Endocrinology 2000; 141: 2683-2690. [Medline] [CrossRef]

17. Giguère V, Hollenberg SM, Rosenfeld MG, Evans RM. Functional domains of the human glucocorticoid receptor. Cell 1986; 46: 645-652. [Medline] [CrossRef]

18. Kovacs JJ, Murphy PJ, Gaillard S, Zhao X, Wu JT, Nicchitta CV, Yoshida M, Toft DO, Pratt WB, Yao TP. HDAC6 regulates Hsp90 acetylation and chaperone-dependent activation of glucocorticoid receptor. Mol Cell 2005; 18: 601-607. [Medline] [CrossRef]

19. Nogami H, Yamamoto N, Hiraoka Y, Aiso S, Sugimoto K, Yoshida S, Shutoh F, Hisano S. Rapid induction of the growth hormone gene transcription by glucocorticoids in vitro: possible involvement of membrane glucocorticoid receptors and phosphatidylinositol 3-kinase activation. J Neuroendocrinol 2014; 26: 195-204. [Medline] [CrossRef]

20. Nogami H, Inoue K, Kawamura K. Involvement of glucocorticoid-induced factor(s) in the stimulation of growth hormone expression in the fetal rat pituitary gland in vitro. Endocrinology 1997; 138: 1810-1815. [Medline] [CrossRef]

21. Bossis I, Porter TE. Evaluation of glucocorticoid-induced growth hormone gene expression in chicken embryonic pituitary cells using a novel in situ mRNA quantitation method. Mol Cell Endocrinol 2003; 201: 13-23. [Medline] [CrossRef]

22. Ellestad LE, Puckett SA, Porter TE. Mechanisms involved in glucocorticoid induction of pituitary GH expression during embryonic development. Endocrinology 2015; 156 1066-1079. [Medline] [CrossRef] 